\title{
Cierre de las escuelas en entornos rurales ¿por o para el despoblamiento?
}

La escuela en entornos rurales ha sido objeto de estudio en relación con aspectos fundamentalmente didácticos; sin embargo, su función como organización social presenta elementos para el análisis. Se reflexiona desde estas líneas sobre el papel de las escuelas en los procesos de despoblación para determinar su contribución como causa o consecuencia de la despoblación rural. Para ello consideraremos los vínculos entre establecimiento de escuelas y evolución demográfica de los municipios que las acogen, su función social en el éxodo rural o su valor simbólico, entre otras circunstancias. El despoblamiento es un fenómeno complejo en el que causas y consecuencias se interrelacionan entre sí. Resulta evidente que las dinámicas poblacionales obedecen a distintas variables y muestran cierta heterogeneidad en el territorio español. Se constata que la escuela no es la piedra angular para el mantenimiento de la población, pero su permanencia o cierre tienen un importante valor simbólico. Es decir, las escuelas rurales no frenan por sí mismas el despoblamiento porque no contrarrestan otros factores, pero su cierre sí contribuye a reforzar el proceso de despoblación. Se concluye con la idea de que las escuelas rurales aparecen como condición necesaria, pero no suficiente para fijar población en el territorio.

Noelia Morales Romo | Dpto. de Sociología y Comunicación, Universidad de Salamanca

URL de la contribución <www.iaph.es/revistaph/index.php/revistaph/article/view/4388>

Con esta contribución nos proponemos reflexionar sobre las relaciones entre las escuelas rurales y los procesos de despoblación. Para ello consideraremos los vínculos entre establecimiento de escuelas y evolución demográfica de los municipios que las acogen, su función social en el éxodo rural o su valor simbólico, entre otras circunstancias.

De los 46,7 millones de habitantes españoles (PADRÓN, 2018), 9,57 millones residen en hábitats rurales, lo que implica que la población rural comprende un 20,48\% del total de la población española. Cuantitativamente se trata de un colectivo minoritario si lo comparamos con la población urbana, pero indudablemente es un grupo lo suficientemente relevante como para ser tenido en cuenta en las planificaciones políticas, educativas, sanitarias, de servicios sociales y de provisión de servicios en general, además de desempeñar un relevante papel para mantener la cohesión territorial .

El Banco Mundial cifra la pérdida de población rural anual en España en el 1\% (POBLACIÓN, 2017) . Si a este dato le unimos pirámides de población muy envejecidas nos encontramos con una población en edad escolar aún más escasa. Aún así, consideramos que, por criterios como el de justicia social o igualdad de oportunidades, es necesario que el alumnado español tenga acceso a un sistema educativo de calidad independientemente de si vive en un pequeño pueblo o en una gran ciudad. No obstante, la realidad muestra diferencias escolares en función del hábitat. Ya en 1995, Ortega calificó a la escuela rural como "la parienta pobre" en un momento en el que las cifras demográficas de las zonas rurales eran más alentadoras que las actuales.

Si complicado resulta definir el medio rural, del mismo modo, y seguramente como consecuencia de ello, la definición de escuela rural no está exenta de dificultades. Son muchos los estudios que constatan la heterogeneidad de las escuelas situadas en entornos rurales -tipologías que van desde el Centro Rural Agrupado (CRA) a la escuela graduada-, en parte por la organización escolar diferenciada , pero también por otras cuestiones relativas al contexto. La España rural plantea importantes 
elementos diferenciadores en términos demográficos, sociales y culturales. La provisión de servicios encuentra en zonas de interior y del norte del país una serie de dificultades mayores que en el sur y levante, donde la dispersión geográfica es menor, con menos municipios y de mayor tamaño. Esto implica que las escuelas en entornos rurales sean heterogéneas en cuanto a distribución, dispersión y alumnado.

Boix (2004: 13) define a la escuela en el entorno rural como "la escuela unitaria y/o cíclica que tiene como soporte el medio y la cultura rurales, con una estructura organizativa heterogénea y singular (en función de la tipología de la escuela) y con una configuración pedagógico-didáctica multidimensional". Con esta definición, el autor hace referencia fundamentalmente a los CRA. Si bien en el medio rural hay centros educativos con estructuras organizativas similares a las de la ciudad, en esta reflexión nos centraremos en los centros con aulas multinivel por ser los que se encuentran con más frecuencia al borde de la desaparición.

Un estudio de Morales (2013) sobre la evolución poblacional de los municipios integrados en centros educativos, fruto de concentraciones escolares de la provincia de Salamanca, reveló que la implantación de la concentración escolar en un determinado municipio no implicó un aumento ni siquiera el mantenimiento de su población ya que esta, al igual que ocurría con el resto de municipios colindantes, siguió presentando una evolución regresiva.

Pero de nuevo los datos cuantitativos son insuficientes en sí mismos. El trabajo de campo que hemos llevado a cabo en varias investigaciones previas (MORALES ROMO, 2017; 2013) nos ha mostrado que hay municipios con número suficiente de niños y niñas residentes como para mantener la escuela abierta, pero esta ha tenido que cerrar por no llegar a la ratio mínima de 4 alumnos/as. La razón es que las familias escolarizan a sus hijos en centros situados en municipios de mayor tamaño o en las ciudades donde trabajan. Los motivos que alegan son el acceso a más y mejores recursos y actividades extraescolares, así como la socialización de sus hijos con mayor número de niños y niñas.
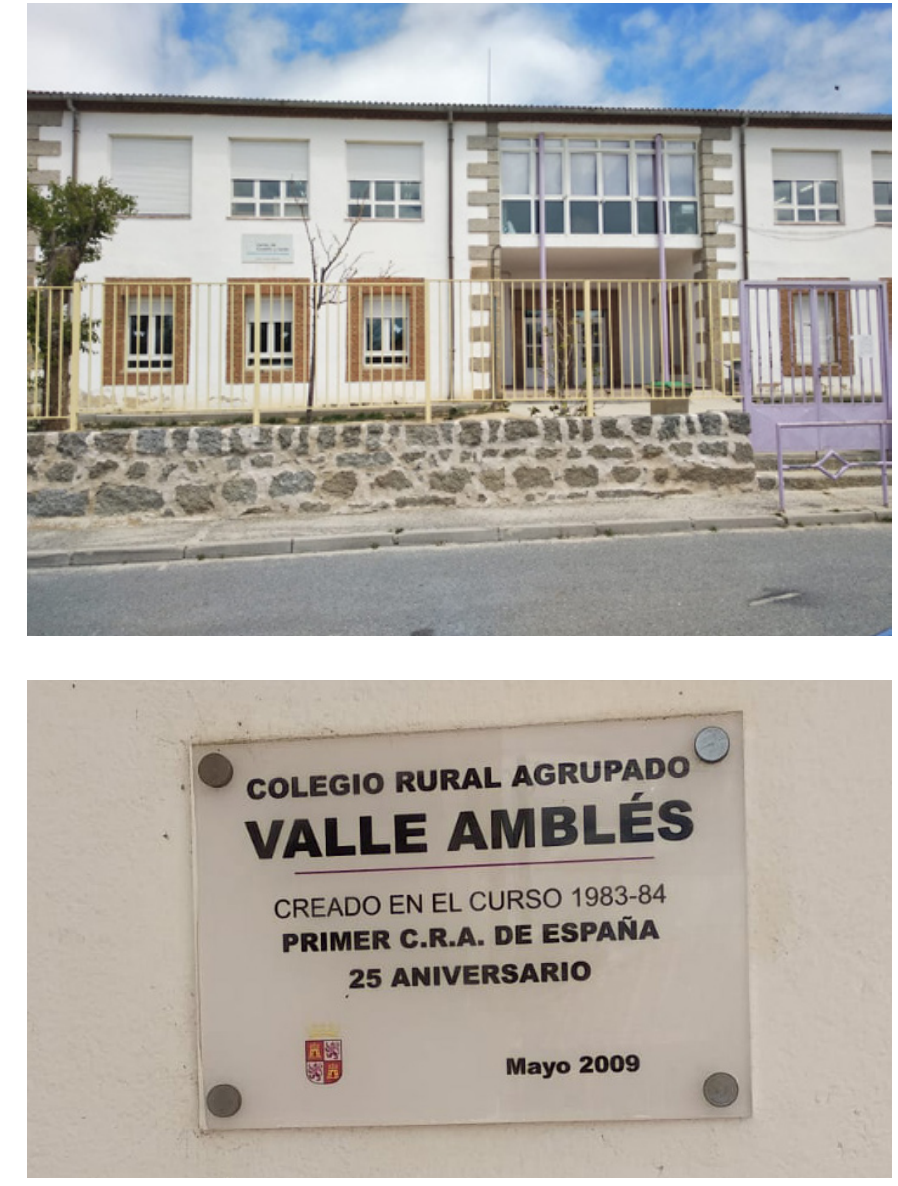

CRA Valle Amblés, el primero que se implantó en España, situado en la provincia de Ávila | fotos Malena González Sánchez

Si bien la escuela por sí sola es posible que no sea un elemento suficiente para atraer a nuevos pobladores, sí constituye uno de los factores que suelen considerar algunas familias jóvenes a la hora de establecer su lugar de residencia. Son muchas las personas entrevistadas que nos han manifestado su sentir de que el cierre de la escuela indica que "el pueblo se muere". Mantener la escuela del municipio hace que los niños y niñas en edad escolar permanezcan en el pueblo durante más tiempo, lleguen varios docentes al mismo y se establezcan unas relaciones sociales entre todos los agentes educativos (docentes, discentes y familias fundamentalmente).

Otro elemento clave al considerar las relaciones entre la escuela rural y el despoblamiento es el papel que ha tenido aquella en el impulso al alumnado que ha pasado 
por ella hacia entornos urbanos para continuar con estudios superiores y/o para buscar un empleo, si bien esto no es exclusivo de entornos rurales sino también de muchas provincias españolas. Por tanto, la educación ha sido una vía de escape del entorno rural (CAMARERO RIOJA; CRUZ SOUSA; GONZÁLEZ FERNÁNDEZ, et ál., 2009).

Un aspecto poco analizado es que la escuela en el medio rural, para aquellos municipios que se debaten entre el mantenimiento o no del centro escolar, corresponde más a un valor simbólico que a una necesidad real. Por el perfil sociodemográfico de los habitantes de los municipios más pequeños, es posible que servicios asistenciales y sanitarios sean más demandados. Los municipios han cambiado y sus escuelas también. No debemos olvidar que lejos quedaron los tiempos en los que maestros y maestras de las escuelas rurales eran residentes de los municipios donde trabajaban y, frecuentemente, parte activa de la vida comunitaria del municipio. En la actualidad la mayoría se desplazan desde municipios mayores y ciudades mientras logran un destino educativo más cercano a sus lugares de residencia. A pesar de estos cambios, las escuelas siguen siendo valoradas positivamente por los habitantes del medio rural donde se ubican, aunque en línea con los planteamientos de otros autores (BENITO LUCAS, 2013), parece que la escuela tiene una influencia limitada, que va unida a las dinámicas territoriales, las estrategias familiares y las influencias de otras instituciones sociales o políticas. La combinación de estos cuatro elementos difiere entre distintas zonas. El cierre de escuelas rurales afecta con mayor intensidad a las comunidades con mayor dispersión y menor densidad poblacional.

Los aspectos cuantitativos por su parte, ofrecen datos nada alentadores: cierre de escuelas, abandono escolar prematuro mayor en el medio rural que en el urbano (SANTAMARÍA LUNA, 2015) aunque entre 2007-2016 se habría reducido (SANTAMARÍA LUNA, 2018). Sin embargo, en sus aspectos cualitativos la escuela rural representa elementos para la ilusión. Por un lado, distintos estudios llevados a cabo en diferentes comunidades autónomas españolas hablan de resultados superiores en el medio rural a igualdad de condición socioeconó- mica y, por otro, diferentes análisis se refieren al valor añadido que aporta la escuela rural (ESCUELA, 2018: 7). Las relaciones que se establecen entre docentes y discentes son mucho más cercanas, más personales, aspecto que puede explicar en parte los buenos resultados que comunidades rurales españolas han obtenido en los últimos datos de PISA y en otros estudios de carácter nacional.

Un claro ejemplo lo encontramos en los últimos resultados de PISA que arrojan unos excelentes datos para Castilla y León, región que, como indica Morales-Romo (2016), está muy marcada por la ruralidad y por dinámicas de población claramente regresivas y, al mismo tiempo, posee un acervo cultural que tradicionalmente ha impulsado los estudios como medio de ascenso social.

Frente al panorama descrito llegamos a la conclusión de que el cierre de las escuelas nunca es voluntario. Aunque sea un recurso utilizado por unas pocas familias, los municipios se resisten a su cierre. Cada cierto tiempo ocupan titulares de prensa iniciativas como la del Ayuntamiento de Cabreros del Río (León) por dotar de ayudas a las familias que mantengan a sus hijos en la escuela del municipio desde preescolar hasta terminar la Educación Primaria. Del mismo modo que otros consistorios tratan de vencer el despoblamiento y el cierre de sus escuelas a través de iniciativas como libros de texto gratis, actividades extraescolares a coste cero o viviendas gratis para familias con hijos.

En definitiva, cuatro conclusiones emergen al analizar la relación entre escuela rural y despoblación.

1. La escuela rural tiene protagonismo en su papel como formadora de educandos que en su mayoría abandonarán a corto plazo su entorno rural para desplazarse a estudiar y/o trabajar en áreas urbanas o periurbanas. A este respecto se intuye una relación contradictoria de la población local en relación con las escuelas: se identifica una clara valoración simbólica de las mismas que hace que el cierre tenga un impacto negativo que la población local ni desea ni busca, pero a la vez, se identifican prácticas contrarias a esta valoración simbólica como resultado del miedo al aislamiento, como se pone de 
manifiesto el matricular a los niños y niñas en escuelas próximas de mayor tamaño.

2. Por otra parte, aunque no le podemos atribuir el poder de ser, en sí misma, un factor de atracción de población, sí tiene un valor simbólico importante en la autoestima de los municipios por considerar el cierre de la escuela un indicador fundamental de su decadencia, además de ser un servicio valorado por familias jóvenes en sus dinámicas de asentamiento poblacional.

3. Se identifica una ambivalencia entre calidad de la educación y arraigo territorial en las escuelas rurales: una alta calidad de la enseñanza, como indica el informe PISA en Castilla-León, que puede y es un factor de arraigo de la población rural, va también unido al abandono de las y los jóvenes del mundo rural, entre otros motivos, para seguir ampliando su formación académica.

4. La escuela rural cuenta con espacios, capital cultural y trayectoria para implantar innovaciones en espacios donde la interacción entre todos los agentes educativos es un recurso inherente. Hay numerosas iniciativas de centros públicos -y también algunos privados dirigidas por neorrurales-, que muestran que la escuela rural puede convertir algunas de sus tradicionales limitaciones en potencialidades en un contexto social donde es clave aunar lo local con lo global. Las nuevas tecnologías y las posibilidades de la escuela rural para acometer innovaciones educativas están fructificando en casos de centros pioneros en innovación educativa.

\section{BIBLIOGRAFÍA}

- BOIX TOMÁS, R. (2004) La escuela rural: Funcionamiento y Necesidades. Barcelona: Praxis, 2004

- camarero RIOJA, L. (coord.); CRUZ SOUSA, F.; GONZÁLEZ FERNÁNDEZ, M. T.; DEL PINO ARTACHO, J. A.; OLIVA SERRANO, J.; SAMPEDRO GALLEGO, R. (2009) La población rural en España. De los desequilibrios a la sostenibilidad social. Barcelona: Fundación La Caixa, 2019 (Colección de estudios sociales, n. ${ }^{\circ} 27$ )

- La ESCUELA rural: una apuesta por la equidad (2018) [en línea] Oviedo: Consejería de Educación y Cultura del Gobierno del Principado de Asturias. Dirección General de Ordenación
Académica e Innovación Educativa, 2018 (Colección Informes de Evaluación, n. ${ }^{\circ}$ 15) <https://www.educastur.es/-/informeevaluacion-n-15-la-escuela-rural-una-apuesta-por-la-equidad> [Consulta: 24/05/2019]

- LUCAS, D. B. (2013) Despoblación, desarraigo y escuela rural: condenados a encontrarse. Encrucijadas-Revista Crítica de Ciencias Sociales, n. ${ }^{\circ}$ 6, 2013, pp. 56-69

- MORALES ROMO, N. (2013) La política de concentraciones escolares en el medio rural: repercusiones desde su implantación hasta la actualidad. Ager: Revista de estudios sobre despoblación y desarrollo rural, n. ${ }^{\circ} 14,2013$, pp. 145188

- MORALES ROMO, N. (2016) El reto de la brecha digital y las personas mayores en el medio rural español. El caso de Castilla y León. Fonseca, Journal of Communication, n. ${ }^{\circ} 13$, 2016, pp. 165-185

- MORALES-ROMO, N. (2017) The Spanish rural school from the New Rural paradigm. Evolution and challenges for the future. Revista Colombiana de Ciencias Sociales, vol. 8, n. ${ }^{\circ} 2$, 2017, pp. 412-438

- ORTEGA PRIETO, M. A. (1995) La parienta pobre (significante y significados de la escuela rural). Madrid: Ministerio de Educación Cultura y Deporte, Centro de Investigación y Documentación Educativa, 1995 (Colección de Investigación, 102)

- PADRÓN Municipal de habitantes (2018) INE, 2018

- POBLACIÓN rural (\% de la población total) (2017) [en línea] Banco Mundial, $2017<$ https://datos.bancomundial.org/ indicador/sp.rur.totl.zs> [Consulta: 06/06/2019]

- SANTAMARÍA LUNA, R. (2015) La escuela rural en entre la LOGSE y la LOMCE: oportunidades y amenazas. Educa Nova: colección de artículos técnicos de educación , 5, 2015, pp. 105150

- SANTAMARÍA LUNA, R. (2018) La Inspección ante la brecha educativa rural-urbano en España. Avances en Supervisión Educativa [en línea], n. ${ }^{\circ}$ 30, $2018<$ https://avances.adide.org/ index.php/ase/article/view/634> [Consulta: 13/06/2019] 